Quality \& Quantity 23: 83-108 (1989)

(C) Kluwer Academic Publishers, Dordrecht - Printed in the Netherlands

Multivariate analysis

\title{
Conditional regression analysis
}

\section{Problems, solutions and an application}

\author{
BAS DENTERS ${ }^{(1)} \&$ ROB A.G. VAN PUIJENBROEK ${ }^{(2)}$ \\ "Department of Public Administration, University of Twente, The Netherlands; \\ ${ }^{(2)}$ Department of Political Science, Catholic University of Nijmegen. The Netherlands
}

\begin{abstract}
This article deals with the question of whether the inclusion of multiplicative terms to model conditional effects in multiple regression is legitimate. The major arguments in the controversy relating to this subject are reviewed. The main conclusion is that most of the objections against multiplicative terms are based on misinterpretations of the coefficients of conditional models. For the often-ignored possible numerical problems in the estimation of these models, due to multicollinearity, an indirect estimation technique is proposed. The potentials of conditional regression analysis are demonstrated on a concrete example.
\end{abstract}

\section{Introduction ${ }^{1}$}

Social science theories often imply conditional effects of explanatory variables. The voting behaviour of voters having an identical party-identification, for instance, is often thought to differ because of differences in the expected voting behaviour of the members of their peer groups. In this simple example the relation between an independent variable (party-identification) and the dependent variable (voting behaviour) is conditioned by the value of a second "environmental" independent variable (expected voting behaviour of the peer group). Environmental effects that are conditional in nature are but a special case of the much more general phenomenon of conditional effects in explanations in social science theories. The theoretical plausibility of such conditional effects raises the issue of how hypotheses containing such relations should be tested empirically.

The analysis of conditional effects in contingency table analysis is by now an established statistical routine. Through elaboration techniques (Lazarsfeld, 1955) or more sophisticated but basically rather similar methods like loglinear analysis (e.g., Fienberg, 1980) conditional hypotheses can be tested rather conveniently for categorical data. With a dependent variable on 
interval or ratio level and one or more categorical explanatory variables, the researcher may employ Analysis of Variance, another established routine, to test for conditional relations.

The test of conditional hypotheses on interval and ratio variables is less well established however. In the statistical literature the introduction of conditional effects in multiple regression models through the inclusion of multiplicative terms is sometimes presented as a convenient solution. This solution is highly controversial however.

In this article we enter the debate on the question of whether the inclusion of multiplicative terms to model conditional effects in multiple regression analysis is appropriate. In Section 2 of this article we review the major arguments in the controversy on this topic. Our main conclusion is that most of the objections against the inclusion of multiplicative terms in regression models are due to a misinterpretation of the estimates.

One major objection, the possible detrimental effects of multicollinearity, however, is too easily discarded by proponents of the inclusion of multiplicative terms. In Section 2.3 we propose an indirect estimation technique to minimize possible effects of multicollinearity. In Section 3 we employ conditional regression analysis (CRA) on empirical data to illustrate the technique and to provide a concrete example of how the results may be presented in a way facilitating interpretation. This is particularly important since results of conditional regression analyses are often misinterpreted. In Section 4 we make some concluding remarks.

\section{Modelling conditional relationships: equations with multiplicative terms ${ }^{2}$}

In the methodological literature three main objections against the use of models with multiplicative terms are raised:

- it is impossible to interpret the results;

- ratio variables are required and this requirement typically is not met;

- multicollinearity distorts the results.

Friedrich (1982) discusses these arguments extensively and concludes that they are incorrect. He argues that the coefficients in equations with multiplicative terms are easy to interpret. Furthermore, according to Friedrich, ratio variables are not required for a meaningful use of multiplicative terms. Finally, multicollinearity is no more of a problem in equations with multiplicative terms than in equations without such terms.

Friedrich's discussion deals with relatively simple models with only one multiplicative term. We will generalize his approach to more complex 
models. We will further propose a procedure that can handle the problem of multicollinearity.

\subsection{Interpretation of regression coefficients}

In regression analysis one models the causal effects ${ }^{3}$ of one or more independent variable(s), $X_{i}$, on a dependent variable, $Y$. The effect of each of the independent variables on $Y$ can be described by means of a partial derivative, $\delta Y / \delta X_{i}$ (Stolzenberg, 1979).

If no conditional relation between independent variables is hypothesized, the appropriate regression equation ${ }^{4}$ (in a model with two independent variables) is:

$$
Y=b_{0}+b_{1} * X+b_{2} * Z
$$

with

$$
\delta Y / \delta X=b_{1}, \quad \delta Y / \delta Z=b_{2}
$$

The partial derivative $\delta Y / \delta X$ represents the effect of $X$ on $Y$. For equation (1) this effect is equal to $b_{1}$. The partial derivative $\delta Y / \delta Z$ is $Z$ 's effect on $Y$ and this effect is equal to $b_{2}$ in equation (1). The effects of $X$ and $Z$ are general; that is to say the effects of these variables do not vary with the value of the other independent variable in the equation.

If a conditional relation between two variables is expected the standard solution is the addition of a multiplicative term to equation (1) (see for example Blalock, 1972; 463-464).

$$
Y=b_{0}+b_{1} * X+b_{2} * Z+b_{3} *(X * Z)
$$

with

$$
\delta Y / \delta X=b_{1}+b_{3} * Z
$$

Suppose that on theoretical grounds one hypothesizes that the effect of $X$ (e.g., party-identification) on $Y$ (e.g., voting behaviour) depends on the value of $Z$ (e.g., expected voting behaviour of peer group). The partial derivative for $X(\delta Y / \delta X)$ in (2) shows that the addition of a multiplicative term is an adequate solution for modelling such a conditional effect: the value of $\delta Y / \delta X$, representing $X$ 's effect on $Y$, is a function of $Z$. 
The interpretation of the coefficients can be facilitated by rewriting (2):

$$
Y=\left(b_{0}+b_{2} * Z\right)+\left(b_{1}+b_{3} * Z\right) * X .
$$

All the coefficients in this equation have a clear interpretation. First there is the term $\left[b_{1}+b_{3} * Z\right]$. This is, as we saw before, the partial derivative $\delta Y / \delta X$; it represents the effect of $X$ on $Y$. In geometric language $\delta Y / \delta X$ forms the slope of the regression plane of $Y$ and $X$. The effect (or the slope) depends, besides on $Z$ 's value, on the coefficients $b_{1}$ and $b_{3}$. Here $b_{1}$ gives the effect on $Y$ of a change in $X$, if $Z$ equals zero, while $b_{3}$ gives the change in the effect of $X$ on $Y$ due to a change in $Z$. For the evaluation of the conditional relation between $X$ and $Y$, this coefficient $b_{3}$ is of special interest. If it is negligible or even zero, the effect of $X$ on $Y$ is to be considered general rather than conditional.

Secondly, there is the term $\left[b_{0}+b_{2} * Z\right]$. This is the sum of all parts of the equation that are irrelevant for the determination of $X$ 's effect on $Y$. It constitutes, in geometric language, the intercept of the line representing the relation of $X$ and $Y$. This intercept depends on, beside $Z$ 's value, the coefficients $b_{0}$ and $b_{2}$. Here $b_{0}$ gives the value of $Y$ if both $X$ and $Z$ are zero. The coefficient $b_{2}$ represents the change in $Y$ due to a change in $Z$ if $X$ is zero.

This exposition shows that the interpretation of the coefficients of (2) is in conditional rather than general terms. This marks a clear contrast with equation (1).

This can be illustrated graphically too, as is done in Figure 1. Figure 1a shows the bivariate relation between $X$ and $Y$. Here $X$ has a positive effect on $Y$. This effect is equal to $b_{1} . Z$ plays no role. Figure $1 \mathrm{~b}$ corresponds to (1). The effect of $X$ on $Y$ does not vary with the value of $Z$ (parallel lines), but the cutting-point with the $Y$-axis depends on $Z .{ }^{5}$ Equation (2) can be represented graphically as is shown in Fig. Ic. The cutting-point with the $Y$-axis and the effect of $X$ on $Y$ vary with the value of $Z{ }^{6}{ }^{6}$ So this is a conditional effect.

The parameters of (2) can be estimated by ordinary least squares procedures as implemented in most popular statistical packages as SAS, SPSS $^{\mathrm{x}}$ and BMDP. The regressors are $X, Z$ and $P$, where $P$ is the product of $X$ and $Z$.

The use of multiplicative terms to model conditional relations widely raised suspicion however. The results obtained are allegedly "arbitrary nonsense" (Cohen, 1978: 861). Friedrich argues convincingly that this allegation is based on invalid arguments. These arguments are derived from a misinterpretation of the results of regression analysis. This erroneous interpretation disregards the conditional nature of equation (2). It simply equates the coefficients $b_{1}$ and $b_{2}$ in both equation (1) and (2) with the effects 


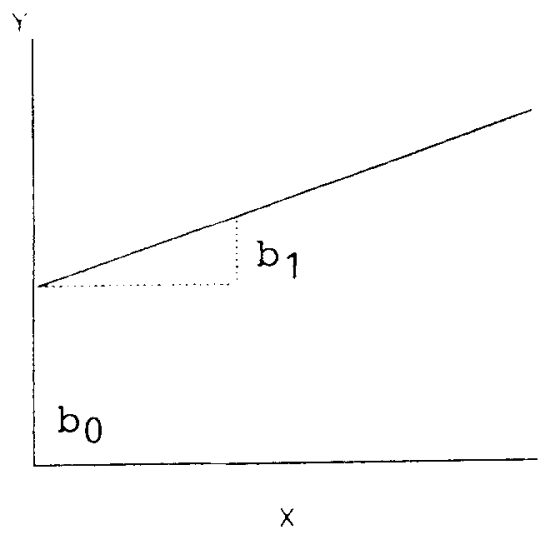

(a)

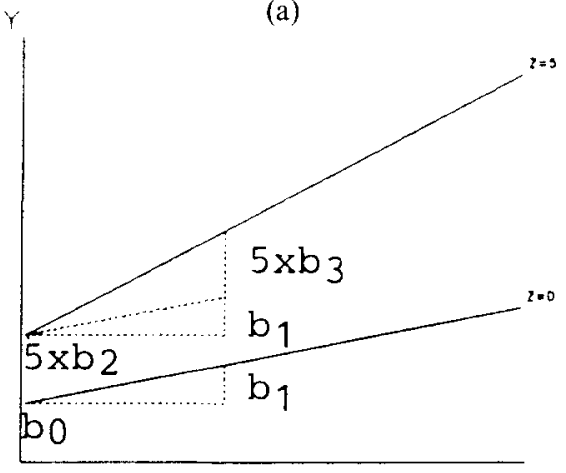

$x$

(c)

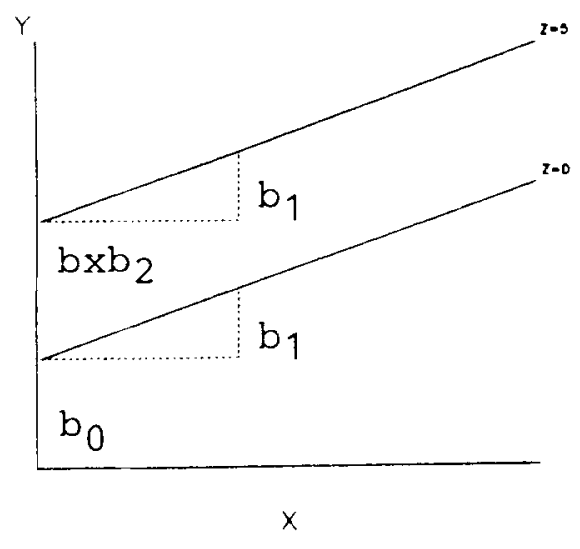

(b)

Fig. I. (a) Bivariate regression. (b) Multivariate regression: equal slopes. (c) Multivariate regression: unequal slopes.

of $X$ and $Z$ on $Y$. As we showed above with the help of partial derivatives this is accurate for equation (1) but it is definitely incorrect for equation (2). In equation (1), $b_{1}$ for instance gives the effect of $X$ on $Y$, irrespective of the value of $Z$. In equation (2), however, $b_{1}$ has no interpretation in terms of a general effect. It has a conditional interpretation only: it represents the effect of $X$ on $Y$ if (and only if) $Z$ is zero!

On the basis of a comparison of the estimates of for instance $b_{1}$ in both equations (1) and (2), showing vast differences between these parameters, critics of multiplicative terms argued that $b_{1}$ in the conditional model is arbitrary and uninterpretable. Since however $b_{1}$ in equation (1) and $b_{1}$ in equation (2) describe different things, it no wonder that they differ. So the critics' argument in this matter is mistaken.

So far we discussed equations with only one multiplicative term. As we will show the argument can be extended easily in at least two ways:

- more than one "conditional" variable

- more than one "independent" variable. 
These extensions do not inflict on the basic logic of the interpretation of the model's coefficients.

More conditions. Equation (3) presents a model with one "independent" variable, $X$, and two conditions, $Z$ and $T$.

$$
Y=b_{0}+b_{1} * X+b_{2} * Z+b_{3} * T+b_{4} * X * Z+b_{5} * X * T
$$

with

$$
\delta Y / \delta X=b_{1}+b_{4} * Z+b_{5} * T, \text { intercept }=b_{0}+b_{2} * Z+b_{3} * T .
$$

The interpretation should be clear by now. The intercept is a function of $Z$ and $T$. The effect of $X$ on $Y$ also varies with the values of $Z$ and $T$. Here $b_{4}$ gives the impact of a change of $Z$ on the effect of $X$ on $Y$ and $b_{5}$ gives the impact of a change of $T$ on this effect. Generalizations to situations with three or more conditions follow the same line of argument.

More "independent" variables. Equation (4) shows a model with two "independent" variables, $X$ and $T$, and one condition, $Z$.

$$
Y=b_{0}+b_{1} * X+b_{2} * T+b_{3} * Z+b_{4} * X * Z+b_{5} * T * Z
$$

with

$$
\begin{aligned}
\delta Y / \delta X & =b_{1}+b_{4} * Z, \\
\delta Y / \delta T & =b_{2}+b_{5} * Z, \\
\text { intercept } & =b_{0}+b_{3} * Z .
\end{aligned}
$$

This equation has an easy interpretation too. First, the intercept is a function of $Z$. Furthermore the effects of $X(\delta Y / \delta X)$ and $T(\delta Y / \delta T)$ on $Y$ vary with $Z$. Here $b_{4}$ and $b_{5}$ give the impact of $Z$ on the effect of $X$ on $Y$ and of $T$ on $Y$ respectively.

We may conclude, therefore, that the generalization of the conditional interpretation of equations with multiplicative terms to more complex models poses no additional problems.

\section{Conditional $t$-values}

In order to test for the statistical significance of the effect of a variable at a specific value of the conditional variable(s), conditional $t$-values are needed. 
Friedrich derives conditional standard errors for equations with one multipicative term (equation (2)).

The conditional standard error, $S$, for the effect of $X$ on $Y$, can be computed by means of the following formula (see Friedrich, 1982: 810):

$$
S^{2}\left(b_{1}+b_{3} * Z\right)=\left[\left(\operatorname{var}\left(b_{1}\right)+Z^{2} * \operatorname{var}\left(b_{3}\right)+2 * Z * \operatorname{cov}\left(b_{1}, b_{3}\right)\right]\right.
$$

This formula shows that the standard errors in equations with multiplicative terms are a function of the value of the conditional variable, just like the effect parameters themselves.

Conditional $t$-values can simply be obtained by dividing conditional effect parameters by their standard errors:

$$
t\left(b_{1}+b_{3} * Z\right)=\frac{b_{1}+b_{3} * Z}{S\left(b_{1}+b_{3} * Z\right)}
$$

The computation of conditional standard errors and $t$-values can also easily be extended to more complex situations.

More conditions. The formulas for the computation of conditional standard errors, $S$, and $t$-values, $t$, for equation [3] are:

$$
\begin{aligned}
S^{2}\left(b_{1}+b_{4} * Z+b_{5} * T\right)= & {\left[\left(\operatorname{var}\left(b_{1}\right)+Z^{2} * \operatorname{var}\left(b_{4}\right)+T^{2} * \operatorname{var}\left(b_{5}\right)\right.\right.} \\
& +2 * Z * \operatorname{cov}\left(b_{1}, b_{4}\right)+2 * T * \operatorname{cov}\left(b_{1}, b_{5}\right) \\
& \left.+2 * Z * T * \operatorname{cov}\left(b_{4}, b_{5}\right)\right] \\
t\left(b_{1}+b_{4} * Z+b_{5} * T\right)= & \frac{b_{1}+b_{4} * Z+b_{5} * T}{S\left(b_{1}+b_{4} * Z+b_{5} * T\right)} .
\end{aligned}
$$

More "independent" variables. In this case the procedure consists of applying formulas [5] and [6] for each of the "independent" variables, separately.

This section leads us to two conclusions. First, the interpretation of the coefficients in conditional regression models poses no major problems. Even in more complex models, with more conditions and/or more independent variables, all the regression coefficients are easy to interpret. Secondly, for both simple and for more complex models, standard errors and $t$-values for conditional effect estimates can be computed. This enables us to evaluate the statistical significance of these estimates. 


\subsection{Level of measurement: are ratio variables required?}

A second argument against the use of regression equations with multiplicative terms concerns the level of measurement. The classical argument is that we need ratio variables (Allison, 1977; Southwood, 1978). We will shortly outline this argument.

Ratio variables require a scale with a meaningful zero point. An example of a ratio variable is "salary in dollars". A score " 0 " on this variable means that someone has no income at all. However, many variables in social science have no such natural minimum. It makes no sense for instance, to say that a score of " 0 " on a development scale means that a country is totally undeveloped.

If a variable has no zero point but the difference between for example " 1 " and " 5 " can be interpreted to be equal to the difference between " 26 " and " 30 " we have to do with an interval variable. If a variable has no fixed zero point, the addition (or substraction) of a constant to all the scores does not alter the intrinsic meaning of the variable. But what are the consequences of such arithmetical operations for the b coefficients?

As is clear from equations (9) and (9a), in an additive equation the constants, $v$ and $w$, are completely incorporated in $b_{0} ; b_{1}$ and $b_{2}$, measuring the effect of $X$ and $Z$, do not change.

$$
\begin{aligned}
& Y=b_{0}+b_{1} *(X+v)+b_{2} *(Z+w) \\
& Y=\left(b_{0}+b_{1} * v+b_{2} * w\right)+b_{1} * X+b_{2} * Z .
\end{aligned}
$$

However, in equations with a multiplicative term the consequences are more complex:

$$
\begin{aligned}
Y= & b_{0}+b_{1} *(X+v)+b_{2} *(Z+w)+b_{3} *(X+v) *(Z+w) \\
Y= & \left(b_{0}+b_{1} * v+b_{2} * w+b_{3} * v * w\right)+\left(b_{1}+b_{3} * w\right) * X \\
& +\left(b_{2}+b_{3} * v\right) * Z+b_{3} * X * Z .
\end{aligned}
$$

As equations (10) and (10a) show, the constants are only partly incorporated in the intercept, $b_{0}$. The regression coefficient for each regressor depends on the constant of the other regressor. However, adding constants to $X$ and $Z$ does not change the coefficient of the multiplicative term, $b_{3}{ }^{7}$ This induces 
many critics to claim that for interval data only the coefficient for the multiplicative term, $X * Z$, has a meaningful interpretation (Allison, 1977; Arnold and Evans, 1979; Arnold, 1982).

Friedrich rejects this conclusion. Central to his argument is again that we must follow the "conditional" interpretation. He repeats his argument that the regression coefficients for $X$ and $Z$ do not describe the general effects of $X$ and $Z$, but specific conditional effects, e.g., for $Z=0$ and $X=0$ (see also Marsden, 1981: 108). If we compute regression coefficients for the equations (2) and (10), and we compare the coefficients for $X$ and $Z$ it must be clear that they are necessarily different. They describe different situations.

If $Z$ runs, for example, from -10 to 10 , then the $b$ coefficient for $X$ reflects the effect of $X$ on $Y$ for $Z=0$. If we add 5 to $Z$, so $w=5$, then $b_{1}$ describes the situation for the new $Z=0$, that corresponds to the old $Z=-5$. If we want to compare coefficients we have to look at, for example, the conditional coefficient for $Z=-5$ in the original equation and the conditional coefficient for $Z=0$ in the second equation. And they are, as can be shown algebraically, the same.

The conclusion must be that ratio variables are not required if we recognize the conditional character of equations with multiplicative terms.

\subsection{Multicollinearity}

The final argument against the use of equations with multiplicative terms concerns the problem of multicollinearity. The correlations between the multiplicative term and one or both of its components are typically quite high. Multicollinearity can lead to highly unstable estimates, which are very sensitive to small changes in the data set.

The problem of multicollinearity has at least two aspects. Firstly, multicollinearity produces excessively large variances and covariances of the regression coefficients (see for example Johnston, 1972: 160). Secondly, numerical problems can arise. Inversion of the correlation/covariance matrix forms part of most regression procedures. The inversion of a matrix with high correlations, and consequently a very small determinant, can give highly inaccurate results.

Friedrich (1982: 809-818) oniy discusses the first aspect. In a rather lengthy argument he stresses several important points. Critics of the conditional model claim that the standard error of an independent variable in such a model (e.g., $s\left(b_{1}\right)$ in equation (2)) is often much larger than the standard error of that variable in the additive model (e.g., $s\left(b_{1}\right)$ in equation (1)). The inflation of the standard error is interpreted as evidence for multicollinearity. Friedrich's first point is that, here too, the critics neglect the conditional 
nature of the model in equation (2). In the additive model, $s\left(b_{1}\right)$ describes the variability of the effect of $X$ on $Y$ (i.e., the coefficient $b_{1}$ ) as constant across all levels of $Z$. In the conditional model, however, $s\left(b_{1}\right)$ describes the variability of $X$ 's effect at a particular level of $Z$. To be more precise, $s\left(b_{1}\right)$ is the conditional standard error of $X$ 's effect on $Y$ (the coefficient $s\left(b_{1}+b_{3}\right)$ from equation (5)), if $Z$ equals zero, as can be easily verified. Secondly, Friedrich points out that the coefficient $s\left(b_{1}\right)$ in a conditional model is not necessarily larger than its counterpart in an additive model, though this will often prove to be the case. Furthermore, if $s\left(b_{1}\right)$ in the conditional model turns out to be larger than the value of the corresponding coefficient in the additive model, the conditional standard error $s\left(b_{1}+b_{3}\right)$ will, at some other values of $Z$, be smaller than $s\left(b_{1}\right)$ from the additive model, provided that a conditional model is appropriate for the data. This may be true, one might object, but this does not invalidate the argument that, at the other values of $Z$, the variability of the effect of $X$ is larger than the (general) standard error of the estimate for $X$ 's effect (i.e., $s\left(b_{1}\right)$ ) in the additive model. But as Friedrich stresses, in both the additive and the conditional model

"descriptions of the relationship between the dependent variable and one independent variable at a particular level of another independent variable become less certain with increasing distance from the center of the regression surface. The only difference is that in the additive model this uncertainty is 'hidden' in the often-ignored standard errors for the intercept and the slope of the other independent variable, while in the interactive model it emerges explicitly in the standard error for the slope of the independent variable of interest as well". (Friedrich: 817).

Finally, Friedrich rightly points out that, although it must be conceded that a conditional model is more sensitive to the particular set of data than an additive model, this is because this model asks a much more detailed question. This being so, it hardly comes as a surprise that the results of such a more detailed analysis are sensitive to details in the data. For this reason one should not, as critics of conditional model often do, interpret this sensitivity as evidence for multicollinearity.

Friedrich pays no attention to potential computational problems, however. In other parts of the literature several estimation procedures have been presented for data sets with high intercorrelations. For example ridge regression, orthogonal regression (Morris et al., 1986) and the QR decomposition method (Belsley et al., 1980: 69-75; Weisberg, 1980: 253-255). 
Smith and Sasaki (1979) developed a method specifically for equations with multiplicative terms. Their starting point is equation (2). Smith and Sasaki show that this equation is a special case of the more general one, presented in equation (11).

$$
Y=b_{0}+b_{1} * X+b_{2} * Z+b_{3} *(X-v) *(Z-w) .
$$

In equation (2) the values of $v$ and $w$ are both zero. Smith and Sasaki prove that the correlations of $X$ and $Z$ with the multiplicative term are a function of $v$ and $w$. Once this is recognized it is attractive to manipulate the values of $v$ and $w$ so as to reduce the correlations practically until zero in order to minimize multicollinearity. Smith and Sasaki give formulas for determining the values of $v$ and $w$ that minimize the correlations of $X$ and $Z$ with the multiplicative term.

$$
\begin{aligned}
& v=\frac{\left(r_{z, p}-r_{x, z} * r_{x, p}\right) * s_{p}}{\left(1-\left(r_{x, z}\right)^{2}\right) * s_{z}} \\
& w=\frac{\left(r_{x, p}-r_{x, z} * r_{z, p}\right) * s_{p}}{\left(1-\left(r_{x, z}\right)^{2}\right) * s_{x}},
\end{aligned}
$$

where:

$$
\begin{aligned}
p & =X * Z . \\
r_{i, j} & =\text { product moment correlation between } i \text { and } j \\
s_{i} & =\text { standard deviation of } i .
\end{aligned}
$$

A possible objection against this approach is that we are not interested in the results of this equation with arbitrary values for $v$ and $w$. It is possible however to calculate the $b$ coefficients and standard errors for equation (2) given the estimates from equation (11). In that case we avoid the numerical errors caused by multicollinearity. Beside we get results that are easy to interpret, following the conditional approach. The formulas for computing the "original" $b$ coefficients are:

$$
\begin{aligned}
& b_{0}^{u}=b_{0}^{c}+v * w * b_{3}^{c} \\
& b_{1}^{u}=b_{1}^{c}-w * b_{3}^{c} \\
& b_{2}^{u}=b_{2}^{c}-v * b_{3}^{c} \\
& b_{3}^{u}=b_{3}^{c},
\end{aligned}
$$


where

$b_{1}^{u}: b$ coefficients equation (2)

$b_{i}^{c}: b$ coefficients equation (11).

In matrix notation:

$$
B^{u}=B^{c} * T^{\prime}
$$

where

$B^{u}$ : vector of $b$ coefficients for equation (2)

$B^{c}$ : vector of $b$ coefficients for equation (11)

$$
T=\left[\begin{array}{cccc}
1 & 0 & 0 & v * w \\
0 & 1 & 0 & -w \\
0 & 0 & 1 & -v \\
0 & 0 & 0 & 1
\end{array}\right]
$$

Along the same lines one can estimate the matrix of variances and covariances of the $b$ coefficients indirectly. ${ }^{8}$ Here too the estimates obtained from equation (11) can be converted in the "normal" parameterization:

$$
V^{u}=T * V^{c} * T^{\prime}
$$

where

$V^{u}:$ (co-) variance matrix $b$ coefficients equation (2),

$V^{c}$ : (co-) variance matrix $b$ coefficients equation (11).

On the basis of formula (14) and (15) we can compute $t$-values too.

The generalization of the Smith and Sasaki method to more complex models poses no problem. As can be shown, the values of the $v$ and $w$ can be computed separately for each of the multiplicative terms. ${ }^{9}$

The first conclusion from this section is that critics of the conditional approach, often wrongly claim that the, at times rather large, standard errors of the conditional effect estimates and the sensitivity of the results of the conditional analyses are evidence for severe multicollinearity problems. But, rather than the result of multicollinearity, these phenomena are the 
"natural" consequences of the conditional nature of the model. A second conclusion is that the possible danger of numerical errors in the estimation of the regression coefficients due to multicollinearity can be circumvented by the indirect estimation technique outlined above.

\section{An application: Estimation of a public choice model of local government tax burdens. ${ }^{10}$}

In Section 2 we concluded that the contention that the results of conditional regression analysis (CRA) are uninterpretable is basically mistaken. This is not to say that the interpretation of these results is an altogether easy matter. In this section we propose a way of presenting the results of CRA to facilitate understanding. In our view this presentation transmits the essentials of CRA-results to any student with only basic knowledge of simple regression analysis.

Before we turn to the presentation of results we set out the essentials of the theoretical argument underlying the estimated regression model.

\subsection{Theoretical background}

The research project from which the data are borrowed Denters (1987) tried to explain differences in local tax buriens ${ }^{11}$ between Dutch municipalicies with a simple public choice model. In this model it was assumed that parties have two main goals. First they try to maximize the number of votes. However, vote maximization is not the party's sole objective. With an increasing share of the vote the marginal utility of a one percent increase decreases. This is reflected in a decreasing priority of vote-maximization and an increasing priority of the party's (rank and file membership's) own policy preferences. The realization of these preferences is the second objective of parties. The willingness of the party to compromise on its fundamental principles is thought to be smaller when the need to compete for the electorate's votes is smaller. However, once competition is more intense the need for parties to take the preferences of the local electorate into account is higher. In this way the level of electoral competition influences the relative importance of the party's own policy preferences and the policy preferences of the local electorate as determinants of policies proposed and implemented by the local parties.

With regard to the policy preferences of the electorate we assume that the higher the level of its income (we use the median of the local income distribution as an indicator $)^{12}$ the lower its appreciation of a relatively high 
tax burden per capita will be. This is plausible since the main source of locally raised revenue for Dutch local authorities is a real estate tax.

With regard to the policy preferences of the political parties we focus on the conservative liberal VVD and the social-democratic PVDA. We hypothesize that the VVD has a strong preference for a relatively low tax burden, while the PVDA is willing to accept higher taxes to finance local government services. The stronger the position of the VVD in the local polity, assuming all other things equal, the lower the local tax burden is expected to be, while the reverse is expected for the PVDA. The strength of the position a party holds is measured with an index of voting-power. ${ }^{13}$

As indicated the relative importance of the electoral policy preferences and the political priorities of the parties depends on the level of electoral competition. The higher competition, the stronger the need for parties to take the electoral preferences into account and the less room there is for pursuing their own preferences. These considerations lead us to the formulation of three hypotheses.

Hypothesis 1: The tax burden per capita in a municipality will be higher the lower the median income in this municipality is. This negative relation will be stronger the higher electoral competition in the municipality is.

Hypothesis 2: The tax burden per capita in a municipality will be higher if the voting power of the social-democratic party (PVDA) in the council is higher. This positive relationship will be stronger the lower electoral competition in the municipality is.

Hypothesis 3: The tax burden per capita in a municipality will be lower if the voting power of the conservative liberal party (VVD) in the council is higher. This negative relation will be stronger the lower electoral competition in the municipality is.

In our study we focused on both static and dynamic aspects of electoral competition. The static aspect refers to the number of effective parties. This measure is the inverse of the Hirschmann-Herfindahl index (Laakso and Taagepera, 1979: 4) $\cdot{ }^{14}$ It is a function of the actual number of parties in a municipality and the distribution of votes over these parties. The higher the number of effective parties the more intense electoral competition. The dynamic aspect of competition refers to electoral volatility (for this concept see Pedersen 1983). The lower volatility the more stable the share of the total vote for parties and the less the need to compete for votes. ${ }^{15}$ 


\subsection{Results and interpretation}

The regression model used to test the hypotheses is specified in equation (16) ${ }^{16}$ The coefficients in this equation were estimated ${ }^{17}$ with the indirect estimation technique described in Section 2.3.

$$
\begin{aligned}
\text { TAX }= & {\left[b_{0}+b_{1} * \text { POLCON }+b_{2} *\right. \text { FLUIVO }} \\
& +\left[b_{3}+b_{4} * \text { POLCON }+b_{5} * \text { FLUIVO }\right] * \text { MEDIAN } \\
& +\left[b_{6}+b_{7} * \text { POLCON }+b_{8} * \text { FLUIVO }\right] * \text { BIRSOC } \\
& +\left[b_{9}+b_{10} * \text { POLCON }+b_{11} * \text { FLUIVO }\right] * \text { BIRVVD }
\end{aligned}
$$

where:

TAX $=$ tax burden

POLCON $=$ number of effective parties

FLUIVO $=$ instability of party-choices

MEDIAN $=$ median income

BIRSOC = voting power social-democratic party $(\operatorname{PvdA})$

BIRVVD = voting power conservative liberal party (VVD).

The estimates $b_{4}$ and $b_{5}$ give information relevant for the evaluation of hypothesis $1, b_{7}$ and $b_{8}$ are employed in the test of the second hypotheses while $b_{10}$ and $b_{11}$ are necessary to evaluate the empirical validity of hypothesis 3 . On the basis of hypothesis 1 we expect $b_{4}$ and $b_{5}$ to be negative. Hypothesis 2 implies that we expect $b_{7}$ and $b_{8}$ to be negative while hypothesis 3 leads us to the expectation that $b_{10}$ and $b_{11}$ will be positive. ${ }^{18}$

Table 1 gives the results of our (indirect) estimation of the regression model. In order to evaluate the effects of the electoral and party preferences on tax burdens and more specifically to gauge the impact of both aspects of electoral competition on these effects we used partial derivatives.

Median income and tax burden. As can be seen from Table 1 the overall effect of median income on tax burdens depends on the number of effective parties and electoral volatility. The variations in the effect of median income on the dependent variable due to variations in both aspects of electoral competition can be presented graphically. Figure $2 a$ presents the effects of median income for different combinations of values for the competition-variables. 
Table 1. Estimates of the effects of median income, voting powder PvdA and voting power VVD on tax burden

$$
\begin{aligned}
& \mathrm{TAX}=[24.61-7.06 * \text { POLCON }+0.13 * \text { FLUIVO }] \\
& {[23.36+5.68 * \text { POLCON }-0.06 * \text { FLUIVO }] * \text { MEDIAN }} \\
& (0.50) \quad(1.48) \\
& {[0.26+0.12 * \text { POLCON }-0.00015 * \text { FLUIVO }] * \text { BIRSOC }} \\
& (0.64) \quad(0.32) \\
& {[-1.15+0.16 * \text { POLCON }+0.0009 * \text { FLUIVO }] * \text { BIRVVD }} \\
& (0.61) \quad(0.92)
\end{aligned}
$$

Note: relevant $t$-values between brackets.

This figure is based on the parameter estimates from Table 1. The relevant parameters are summarized in equation (17).

$$
\text { TAX }=a^{\prime}+[23.36+5.68 * \text { POLCON }-0.06 * \text { FLUIVO }] * \text { MEDIAN }
$$

The complex term between brackets represents the effects of median income on tax burdens. This complex term is the partial derivative $\delta \mathrm{TAX} /$ $\delta$ MEDIAN and determines the slope of the function. The $a^{\prime}$-term in this expression, the intercept of the function, is the sum of all the terms from the original regression equation that are irrelevant for the determination of the effect of MEDIAN. ${ }^{19}$

By substituting different values for both competition-variables (POLCON and FLUIVO) we get different intercepts $\mathrm{a}^{\prime}$ and slopes for the function representing the relation of median income and tax burden. ${ }^{20}$

Table $2 \mathrm{a}$ gives us the values of the conditional effect parameters of median income (MEDIAN) for several combinations of values of electoral volatility and the number of effective parties. Figure $2 \mathrm{a}$ represents the relation between median income and the tax burdens for some of the combinations of the composition variables. Function LL in this figure for instance represents the effect of median income on the tax burden for relatively low values of either aspect of competition. (POLCON $=2.06$ and FLUIVO $=352$ ). Function $\mathrm{LH}$ gives the effect of median income when the number of effective parties is relatively low (POLCON $=2.06)$ and electoral volatility is relatively high (FLUIVO $=912$ ). Function HL represents the median income effect when the number of effective parties is relatively high (POLCON $=$ 4.19 ) and electoral volatility is rather low (FLUIVO = 352). And function HH finally gives the effect of median income when both competition variables take relatively high values $(\mathrm{POLCON}=4.19$ and FLUIVO $=912$ ). The dotted line shows the general effect. ${ }^{21}$ This is the effect of the independent variable (e.g., median income) if it is assumed that there is no conditional 
Table 2(a). Conditional $b$ coefficients and $t$-values for median income

\begin{tabular}{ccccccc}
\hline & & \multicolumn{5}{c}{ FLUIVO } \\
\cline { 3 - 7 } & & 71 & 352 & 632 & 912 & 1197 \\
\hline & 1.00 & 24.78 & 7.92 & -8.88 & -25.68 & -42.78 \\
& & $(0.83)$ & $(0.30)$ & $(0.37)$ & $(0.87)$ & $(1.14)$ \\
$\mathrm{P}$ & 2.06 & 30.80 & 13.94 & -2.86 & -19.66 & -36.76 \\
$\mathrm{O}$ & & $(1.24)$ & $(0.81)$ & $(0.22)$ & $(0.99)$ & $(1.25)$ \\
$\mathrm{L}$ & 3.12 & 36.82 & 19.96 & 3.16 & -13.64 & -30.74 \\
$\mathrm{C}$ & & $(1.48)$ & $(1.33)$ & $(0.30)$ & $(0.98)$ & $(1.28)$ \\
$\mathrm{O}$ & 4.19 & 42.90 & 26.04 & 9.24 & -7.56 & -24.66 \\
$\mathrm{~N}$ & & $(1.42)$ & $(1.23)$ & $(0.58)$ & $(0.49)$ & $(1.03)$ \\
& 5.25 & 48.92 & 32.06 & 15.26 & -1.54 & -18.64 \\
& & $(1.27)$ & $(1.04)$ & $(0.58)$ & $(0.09)$ & $(0.65)$ \\
\hline
\end{tabular}

Table 2(b). Conditional $b$ coefficients and $t$-values for voting power of the social democratic party

\begin{tabular}{ccccccc}
\hline & & \multicolumn{5}{c}{ FLUIVO } \\
\cline { 3 - 7 } & & 71 & 352 & 632 & 912 & 1197 \\
\hline & 1.00 & 0.37 & 0.33 & 0.29 & 0.24 & 0.20 \\
& & $(0.78)$ & $(0.78)$ & $(0.72)$ & $(0.58)$ & $(0.43)$ \\
$\mathrm{P}$ & 2.06 & 0.50 & 0.45 & 0.41 & 0.37 & 0.33 \\
$\mathrm{O}$ & & $(1.40)$ & $(1.70)$ & $(1.83)$ & $(1.48)$ & $(1.01)$ \\
$\mathrm{L}$ & 3.12 & 0.62 & 0.58 & 0.54 & 0.50 & 0.45 \\
$\mathrm{C}$ & & $(1.93)$ & $(2.81)$ & $(4.44)$ & $(3.52)$ & $(1.89)$ \\
$\mathrm{O}$ & 4.19 & 0.75 & 0.71 & 0.67 & 0.63 & 0.58 \\
$\mathrm{~N}$ & & $(1.88)$ & $(2.35)$ & $(2.84)$ & $(2.71)$ & $(2.00)$ \\
& 5.25 & 0.88 & 0.84 & 0.80 & 0.75 & 0.71 \\
& & $(1.62)$ & $(1.80)$ & $(1.91)$ & $(1.86)$ & $(1.64)$ \\
\hline
\end{tabular}

Table $2(c)$. Conditional $b$ coefficients and $t$-values for voting power of the conservative liberal party

\begin{tabular}{lcccccc}
\hline & & \multicolumn{5}{c}{ FLUIVO } \\
\cline { 3 - 7 } & & & 352 & 632 & 912 & 1197 \\
\hline & 1.00 & -0.93 & -0.67 & -0.42 & -0.17 & 0.09 \\
& & $(1.06)$ & $(0.90)$ & $(0.58)$ & $(0.19)$ & $(0.12)$ \\
$\mathrm{P}$ & 2.06 & -0.76 & -0.50 & -0.25 & 0.00 & 0.26 \\
$\mathrm{O}$ & & $(1.04)$ & $(0.93)$ & $(0.53)$ & $(0.06)$ & $(0.41)$ \\
$\mathrm{L}$ & 3.12 & -0.59 & -0.33 & -0.08 & 0.17 & 0.43 \\
$\mathrm{C}$ & & $(0.85)$ & $(0.75)$ & $(0.23)$ & $(0.67)$ & $(0.87)$ \\
$\mathrm{O}$ & 4.19 & -0.42 & -0.16 & 0.09 & 0.34 & 0.60 \\
$\mathrm{~N}$ & & $(0.53)$ & $(0.28)$ & $(0.41)$ & $(1.26)$ & $(1.28)$ \\
& 5.25 & -0.25 & 0.01 & 0.26 & 0.51 & 0.77 \\
& & $(0.25)$ & $(0.05)$ & $(0.55)$ & $(1.10)$ & $(1.32)$ \\
& & & & & &
\end{tabular}

Note: $t$-values between brackets. 


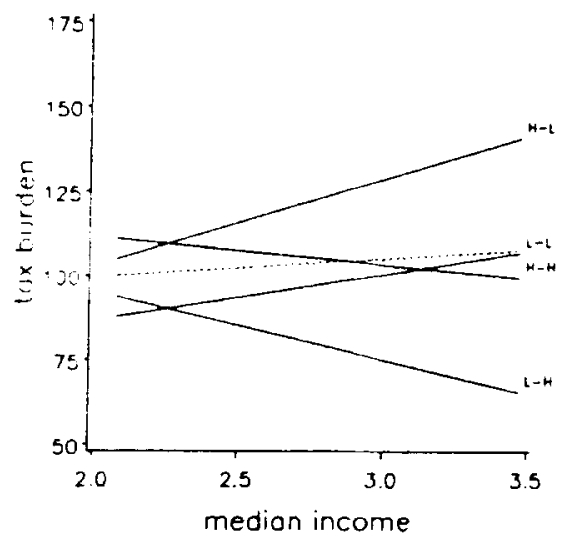

(a)

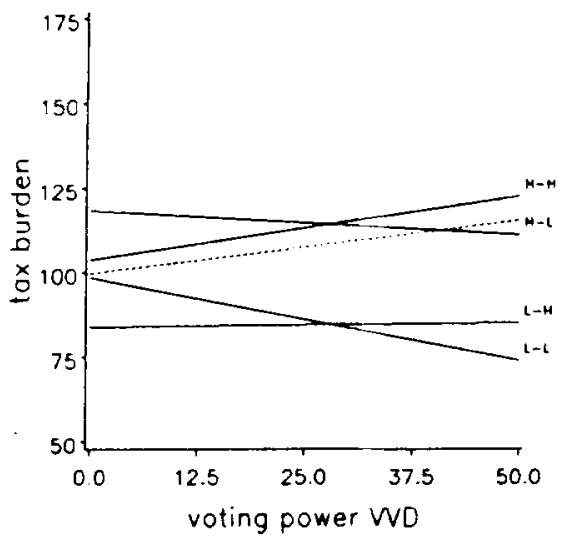

(c)

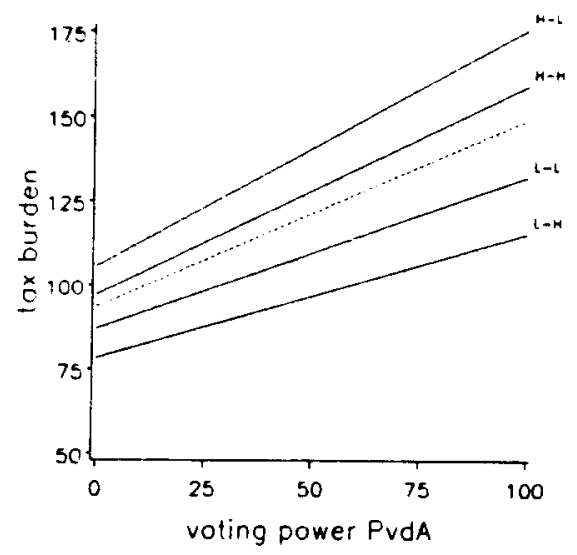

(b)

$$
\begin{array}{ll}
\text { Dotted line } & : \text { general effect } \\
L-L & : \text { polcon low \& } \\
& \text { fluivo low } \\
\text { L } H & \text { polcon low \& } \\
& \text { fluivo high } \\
\mathrm{H}-\mathrm{L} & : \text { polcon high \& } \\
& \text { fluivo low } \\
\mathrm{H}-\mathrm{H} & : \text { polcon high \& } \\
& \text { fluivo high }
\end{array}
$$

Fig. 2. (a) The effect of median income on tax burden. (b) The effect of voting powder PvdA on tax burden. (c) The effect of voting powder WD on tax burden.

(or additive) effect from e.g., electoral volatility or the number of effective parties.

Before we turn to a detailed examination of the regression results, a general observation should be made. If we look at the general effect, the dotted line in Figs. $2 a, 2 b$ and $2 c$, we observe that the results of the additive model in all three cases square nicely with the results from the conditional model. The conditional effects of the independents (median income and the voting power of the PVDA and the VVD) at relatively "extreme" values of the conditions (electoral volatility and the number of effective parties) straddle the general effect in all three cases. This is an altogether reasonable outcome, since from the perspective of a conditional model, the general effect can be conceived of as some kind of a weighted average of the effects 
of $X$ on $Y$ at the different levels of $Z$. This finding is in line with one of the general arguments in this paper: the results from a conditional model are not unreliable, "unnatural" or distorted by multicollinearity. The estimates of the conditional model describes "the relationships in a set of data in a different, more detailed way than the coefficients in an additive model". (Friedrich: 809 ).

A systematic comparison of the four conditional functions enables us to analyse the effects of both aspects of electoral competition on the relation between median income and tax burdens. In comparing function $\mathrm{LL}$ with $\mathrm{HL}$ (or $\mathrm{LH}$ with $\mathrm{HH}$ ) we keep electoral volatility constant while the number of effective parties varies. In this way we can isolate the impact of the number of effective parties on the relation between median income and tax burdens. In comparing function LL with LH (or HL with $\mathrm{HH}$ ) we keep the number of effective parties constant and the impact of electoral volatility can be evaluated. Finally, a comparison of function LL with $\mathrm{HH}$ enables us to appreciate the joint effect of both aspects of electoral competition.

If we compare function LL with $\mathrm{HL}$ in Fig. $2 \mathrm{a}$, we see that the impact of the number of effective parties on the relation between median income and tax burdens is positive (HL is sloping us steeper than $\mathrm{LL}$ ) and not negative as theoretically expected (viz. hypothesis 1). The effect of electoral volatility however is negative (as we can conclude from a comparison of function LL with $\mathrm{LH}$ ) as we expected from hypothesis $1 .^{22}$ The results indicate that hypothesis 1 is only partly corroborated. It is found to give accurate predictions only with regard to electoral volatility but it is inaccurate for the static aspect of electoral competition.

Voting power PvdA and tax burden. Hypothesis 2 implies that the higher the PVDA voting power is, the higher the local tax burden will be. Furthermore this positive relation is to be stronger the weaker electoral competition (in terms of the number of effective parties and electoral volatility) is. We can evaluate this proposition through an inspection of Fig. $2 \mathrm{~b}$, in combination with data from Table 1 and $2 b$. Figure $2 b$ presents the functional relation between PVDA voting power (BIRSOC) and local tax burdens for different levels of electoral competition. The general relation between the variables is given in equation [18]:

$$
\mathrm{TAX}=a^{\prime \prime}+[0.26+0.12 * \mathrm{POLCON}-0.00015 * \text { FLUIVO }] * \mathrm{BIRSOC}
$$

This again is a simple reformulation of the regression equation from Table 1. The complex term between brackets is the partial derivative $\delta \mathrm{TAX} / \delta \mathrm{BIRSOC}$. 
This derivative forms the slope of the function. Again this slope depends on the values of the two competition variables. The term $a^{\prime \prime}$, the function's intercept, is the sum of all the terms of the original equation that are not relevant for the determination of the effect of BIRSOC. ${ }^{23}$ The way in which the relation between social-democratic voting power and tax burdens and intercept vary with both aspects of electoral competition is represented in Fig. $2 b$.

Comparing function LL with HL (or LH with $\mathrm{HH}$ ) shows that an increase in the number of effective parties does not weaken the positive relation between social-democratic voting power and tax burdens. Therefore we conclude that hypothesis 2 is disproved for the static aspect of electoral competition. Furthermore, as the comparison of function LL with LH (or $\mathrm{HL}$ with $\mathrm{HH}$ ) indicates, Fig. 2b shows that the expected negative effect of electoral volatility on the relation between PVDA voting power and tax burdens is only slight. Hypothesis 2 therefore is clearly disproved by our data. It is noteworthy however that, irrespective of the level of electoral competitition, almost all of the coefficients representing the effect of social-democratic voting power on tax burdens in Table $2 \mathrm{~b}$ are statistically significant. This indicates that, no matter how intense electoral competition, a relatively high PVDA voting power is related to a high local tax burden.

Voting power VVD and tax burden. Hypothesis 3 states that the tax burden per capita will be lower the higher the voting power of the conservative liberal VVD. Furthermore this negative relation is expected to be stronger the lower electoral competition is. Figure $2 \mathrm{c}$ and data from Table 1 and $2 \mathrm{c}$ enable us to evaluate this proposition. Figure $2 c$ presents the functional relation of the VVD voting power (BIRVVD) and local tax burdens for different combinations of the two aspects of electoral competition under study. The general relation between tax burdens and VVD voting power is given in equation 19 :

$$
\mathrm{TAX}=a^{\prime \prime \prime}+[-1.15+0.16 * \text { POLCON }+0.0009 * \text { FLUIVO }] * \text { BIRVVD. }
$$

The complex term between brackets is the partial derivative $\delta \mathrm{TAX} /$ $\delta$ BIRVVD and determines the slope of the function. It represents the strength of the effect of the VVD voting power on tax burdens. The strength and sign of this effect depend on the number of effective parties (POLCON) and electoral volatility (FLUIVO). The term $a^{\prime \prime \prime}$, the intercept, is the sum of all the terms in the original equation that are irrelevant for the 
determination of the effect of BIRVVD on tax. ${ }^{24}$ The way in which the effect of VVD voting power and intercept vary with both aspects of competition is represented in Fig. $2 \mathrm{c}$ and Table $2 \mathrm{c}$.

A comparison of function LL with $\mathrm{HL}$ indicates that an increase in the number of effective parties weakens the negative effect of the VVD voting power on tax burdens. A similar pattern can be observed once, through a comparison of function LL with $\mathrm{LH}$, we assess the effect of electoral volatility. The signs of the effects of both competition variables on the relation between VVD voting power and tax burdens are as predicted in hypothesis $3{ }^{25}$ Although neither of these effects is statistically significant in its own right, a comparison of function $\mathrm{LL}$ with $\mathrm{HH}$ indicates that their joint effect is sizeable. This finding can be considered as an - admittedly weak corroboration of the third hypothesis.

\section{Conclusions}

In this article we argued that for interval and ratio variables, a rather convenient method for testing conditional hypotheses is available. The inclusion of multiplicative terms is an appropriate mean to this end. Although this method has been highly controversial in the methodological literature, we showed that the major objections against its use are essentially mistaken.

The essentials of the general argument are illustrated by a substantive example. From this argument it follows that the results of conditional regression analysis are neither "arbitrary nonsense" nor extremely difficult to interpret. Even a relatively complex interaction model can be presented in a way that makes the results comprehensible to any student with an undergraduate's standard knowledge of multivariate statistics.

We would like to add a note of caution however. Models including conditional relations are by definition relatively complex. Because of the scientific ideals of parsimony and simplicity there are good a priori reasons against the inclusion of conditional effects in our models. ${ }^{26}$ Of course parsimony and simplicity are not sacrosanct. If there are sound theoretical reasons for specifying a conditional relation between variables one should not refrain from doing so. In this case a convenient method for testing these propositions is available in the form of conditional regression analysis. In explanatory endeavours however the introduction of multiplicative terms is bound to become yet another toy for those involved in, now even more than ever endless, data-fishing expeditions. 


\section{Notes}

1. We would like to thank Cees Aarts, Ton Bertrand, Peter Geurts, Wil Groenen, Jan Lammers, Jan Van Deth, Leo Van Snippenburg and Piet Verschuren for their comments on an earlier draft.

2. The addition of multiplicative terms to equations is only one way of modelling conditional relationships. See for an overview Southwood (1978) and Stolzenberg (1979).

In some cases researchers have modelled conditional relations by splitting up the units of analysis in two or more subsamples using the (continuous) conditioning variable as the criterion. The relation between the dependent and the independent variable is then estimated in each subsample separately (see e.g., Gobalet and Diamond, 1979; Hansen, 1981; Weede, 1987). In this way however, one throws away information and introduces an unnecessary arbitrary decision (on the cutting points of the continuous conditional variable used to determine the subsamples) into the analysis.

3. We will only discuss unstandardized regression coefficients. The computation of standardized coefficients is possible but gives additional complications. See Friedrich (1982: 823-826).

4. For the sake of simplicity we have dropped the disturbance term $U$ from all the equations.

5. Equation (1) can be rewritten as:

$$
Y=\left(b_{0}+b_{2} * Z\right)+b_{1} * X .
$$

The term between brackets represents the cutting-point with the $Y$-axis. This cutting-point is a function of $Z$.

6. Equation (2) can be rewritten as:

$$
Y=\left(b_{0}+b_{2} * Z\right)+\left(b_{1}+b_{3} * Z\right) * X .
$$

The first part of this equation represents the cutting-point with the $Y$-axis. The second part represents the effect of $X$ on $Y$. Both are a function of $Z$.

7. The same argument holds for the $t$-values. The $t$-values for $b_{1}$ and $b_{2}$ vary with the values of respectively $w$ and $v$, while the $t$-value for the multiplicative term is no function of $v$ or $w$.

8. Formula [4] of Tate, p. 254, is incorrect.

9. The general rules for the construction of the $T$-matrix are:

- initialize an identity matrix with dimensions $(n+1) *(n+1) ; n$ is the total number of regressors, including multiplicative terms

- for each of the multiplicative terms:

* choose the column whose column number corresponds with the rank number of the $b$ coefficient plus one

* put the product of the constants for both components of the multiplicative term in the first row

* place the constant for the first (second) component of the multiplicative term in the row which corresponds to the second (first) component; add a minus sign.

The $T$-matrix for equation [3] is, for example:

$$
T=\left[\begin{array}{cccccc}
1 & 0 & 0 & 0 & v 4 * w 4 & v 5 * w 5 \\
0 & 1 & 0 & 0 & -w 4 & -w 5 \\
0 & 0 & 1 & 0 & -v 4 & 0 \\
0 & 0 & 0 & 1 & 0 & -v 5 \\
0 & 0 & 0 & 0 & 1 & 0 \\
0 & 0 & 0 & 0 & 0 & 1
\end{array}\right] .
$$


10. See for applications of equations with one multiplicative term and a conditional interpretation of the results: Deschouwer (1986); Lange and Garrett, 1985; Letterie and Van Puijenbroek (1985); Van Puijenbroek and Van Snippenburg (1985) and Weede (1987).

11. This dependent variable, to be more precise, is defined as the sum of five local taxes (of which the local property tax is generally by far the most important) divided by the number of inhabitants of the municipality in 1979.

12. This variable is defined as the median of the distribution of personal income (before taxation) in the municipality in 1978. It is measured in units of 10000 Dutch guilders.

13. We employed an adjusted Banzhaf index for this purpose. This index can be defined as the number of times a party is a crucial member of a coalition of minimal policy range divided by the total number of crucial memberships for this type of coalitions (summed over all parties). The rationale for using this index is given in Denters (1987: 79-83). A coalition of minimal policy range is a coalition in which parties have minimized the ideological heterogeneity. For a more detailed discussion of coalition theories see De Swaan, 1973. A party is a crucial member of a coalition if its defection implies that the coalition loses the required simple majority of votes in the municipal council.

14. This measure (POLCON) is formally defined as $1 / \Sigma p_{i}^{2}$, in which $p_{i}$ is the proportion of the total vote for party $i$ (Laakso and Taagepera, 1979: 4). If the parties in a polity have an equal share of the vote the effective number of parties equal the actual number of parties (e.g., in a four party system in which each party receives 25 percent of the vote the number of effective parties is 4 ). The more unequal the distribution of votes over the parties gets the greater the difference between the effective and the actual number of parties gets (e.g., in a four party system in which one party gets 99 percent of the vote and the remaining three parties together attract only one percent, the effective number of parties will be close to 1 ).

15. Electoral volatility is defined here as the average change in the proportion of the total vote for a party-bloc in the municipal elections of 1970, 1974 and 1978. We distinguished six party-blocs (extreme left, centre left, christian-democrats, conservative liberal and extreme right).

16. The intercept of equation (16), also contains the effect of another aspect of electoral competion, electoral volatility due to fluctuations in turnout. The effect of this variable was expected to be linear additive and not conditional. The variable was included in the basic model but for the sake of simplicity we didn't discuss its effect in this article. The inclusion of this variable in no ways affects the results of the analyses. The intercept was computed by adding the product of the regression coefficient for this aspect of competion $(0.02)$ and the mean of this variable (413.28) to the "normal intercept" of the equation (15.28).

17. The model was estimated with INTERACT, a computer program developed by R.A.G. Van Puijenbroek (Social and Cultural Planning Bureau, P.O. Box 37, 2280 AA Rijswijk, The Netherlands). It is written in SAS-IML and REXX. INTERACT computes among others conditional $\mathbf{b}$ coefficients and t-values. A full screen version is available for IBM (compatible) mainframes under VM/CMS.

We also estimated the models with other regression procedures. The results were identical. We also found no difference between the results obtained by the indirect estimation technique and the traditional (direct) estimation procedures.

18. (a) Because we do not have a simple random sample the use of statistical tests for inferential purposes is illegitimate. In our research we used test-statistics as - admittedly rather arbitrary - criteria for substantive significance. In our analyses the size of the $t$-values (a critical $t$-value of 1.28 ; corresponding to a significance level of $10 \%$, 
one-sided test) of two parameters are of special interest. First the coefficients $b_{4}, b_{5}$, $b_{7}, b_{8}, b_{10}, b_{11}$ from equation (16). If the $t$-value of these coefficients exceeds the critical value and its sign is as predicted we consider the relevant hypothesis (on the impact of POLCON and/or FLUIVO on the conditional slopes) to be corroborated. Second the $t$-values of the conditional slopes. Even through neither of the $t$-values of the coefficients representing the impact of POLCON and FLUIVO on the conditional slope (e.g., $b_{4}$ and $b_{5}$ on the relation of MEDIAN and TAX) may be significant, some or even all of the $t$-values of conditional slopes may exceed the critical value. Sometimes this is the reflection of a sizeable joint effect of POLCON and FLUIVO (through the $t$-values of the impact of neither of these need to be significant) on the conditional slopes. In such a case we may consider a hypothesis to be (weakly) corroborated even through the impacts of POLCON and FLUIVO in their own right do not meet the criterion of significance.

(b) Because small cities were underrepresented in our sample, we weighted the cases. Tests of statistical significance are normally based on the weighted sample size. If the weighted number of cases exceeds the sample size tests of significance are inflated. In order to correct for this inflation we used a weighting procedure as described in the SPSSx User's Guide (1986: 186).

19. The constant $a^{\prime}$ does not only depend on the values of POLCON and FLUIVO, but also on BIRSOC and BIRVVD. The value of $a^{\prime}$ is computed by substituting the desired values for POLCON and FLUIVO in the equation while substituting the means for BIRSOC and BIRVVD:

$$
\begin{aligned}
a^{\prime}= & 24.61-7.06 * \quad \text { POLCON }+0.13 * \quad \text { FLUIVO } \\
& +(0.26+0.12 * \text { POLCON }-0.00015 * \text { FLUIVO) } * \text { mean (BIRSOC) } \\
& +(-1.15+0.16 * \text { POLCON }+0.0009 * \text { FLUIVO }) * \text { mean }(\text { BIRVVD })
\end{aligned}
$$

where: mean $($ BIRSOC) $=16.11$, mean $($ BIRVVD) $=8.93$.

20. In the tables, five values for both POLCON and FLUIVO are specified and conditional effect parameters for MEDIAN, BIRSOC and BIRVVD were computed. For POLCON the two "extreme" values in the table are the minimum and the maximum for this variable in our sample. The middle value is close to POLCON's mean and the two remaining values are at approximately one standard deviation distance from this central value. For FLUIVO practically the same procedure was employed but here we did not use the actual maximum of this variable but a less 'extreme' value. This was done because FLUIVO's distribution was skewed to the right. In the figures the conditional effects for only two values (those at one standard deviation of the mean) are represented graphically.

21. We estimated the parameters for the following equation:

$$
\text { TAX }=b_{0}+b_{1} * \text { MEDIAN }+b_{2} * \text { BIRSOC }+b_{3} * \text { BIRVVD }
$$

We then followed the same approach as in the case of conditional effects.

$$
\begin{array}{lll}
\text { Slope MEDIAN: } & b_{1} \\
\text { Intercept MEDIAN: } & b_{0}+b_{2} *(\text { mean BIRSOC })+b_{3} *(\text { mean BIRVVD }) \\
\text { Slope BIRSOC: } & b_{2} \\
\text { Intercept BIRSOC: } & b_{0}+b_{1} *(\text { mean MEDIAN })+b_{3} *(\text { mean BIRVVD }) \\
\text { Slope BIRVVD: } & b_{3} \\
\text { Intercept BIRVVD: } & b_{0}+b_{1} *(\text { mean MEDIAN })+b_{2} *(\text { mean BIRSOC }) .
\end{array}
$$


22. Because of the positive impact of the number of effective parties (POLCON) and the intercept in the second term between brackets in the regression equation the relation between MEDIAN and TAX is not negative for all combinations of values of POLCON and FLUIVO.

23. $a^{\prime \prime}=24.61-7.06 *$ POLCON $+0.13 *$ FLUIVO

$$
\begin{aligned}
& +(23.36+5.68 * \text { POLCON }-0.06 * \text { FLUIVO }) * \text { mean (MEDIAN) } \\
& +(-1.15+0.16 * \text { POLCON }+0.0009 * \text { FLUIVO) } * \text { mean }(\text { BIRVVD) }
\end{aligned}
$$

where: mean $($ MEDIAN $)=2.55$, mean $($ BIRVVD $)=8.93$

24. $a^{\prime \prime \prime}=24.61-7.06 *$ POLCON $+0.13 *$ FLUIVO

$$
\begin{aligned}
& +(0.26+0.12 * \text { POLCON }-0.00015 * \text { FLUIVO }) * \text { mean }(\text { BIRSOC }) \\
& +(-1.15+0.16 * \text { POLCON }+0.0009 * \text { FLUIVO }) * \text { mean }(\text { BIRVVD })
\end{aligned}
$$

where: mean $($ MEDIAN) $=2.55$, mean $($ BIRSOC $)=16.1 \mathrm{l}$.

25. Because of the large negative constant in the fourth term between brackets in the regression equation, the relation between BIRVVD and TAX is not negative for every combination of values of POLCON and FLUIVO.

26. Friedrich appears to favour another position. He claims that: "In the face of the weakness of the arguments against multiplicative terms, the arguments for including such terms become compelling. An interactive model can provide an accurate and more detailed description of the relationships in a set of data, increased explanatory power, and an improvement in the prospects for statistically significant results". (Friedrich, 1982: 832).

\section{References}

Allison, P.D. (1977). "Testing for interaction in multiple regression", The American Journal of Sociology 83: 144-153.

Arnold, H.J. (1982). "Moderator variables: a clarification of conceptual, analytic, and psychometric issues", Organizational Behavior and Human Performance 29: 143-174.

Arnold, H.J. \& Evans, M.G. (1979). "Testing multiplicative models does not require ratio scales", Organizational Behavior and Human Performance 24: 41-59.

Belsley, D. A., Kuh, E. \& Welsh, R. E. (1980). Regression Diagnostics: Identifying Influential Data and Sources of Collinearity. New York: John Wiley \& Sons.

Blalock, H.M. Jr (1972). Social Statistics. 2nd edn. Tokyo: McGraw-Hill.

Cohen, J. (1978). "Partialed products are interactions; partialed powders are curve components", Psychological Bulletin 85: 858-866.

Denters, B. (1987). Partijen, kiezers en gemeentelijke beleid; een empirische toetsing van een politiek-economische theorie. Amsterdam: CT-Press.

Deschouwer, K. (1986). "Excellente partijen: een theoretische en empirische exploratie", Mens en Maatschappij 61: 340-362.

De Swaan, A. (1973). Coalition Theories and Cabinet Formations, a Study of Formal Theories of Coalition Formation as Applied to Nine European Parliaments after 1918. Amsterdam: Elsevier. 
Fienberg, S.E. (1980). The Analysis of Cross-Classified Categorical Data. 2nd edn. Cambridge: MIT Press.

Friedrich, R.J. (1982). "In defense of multiplicative terms in multiple regression equations", American Journal of Political Science 26: 797-833.

Gobalet, J.G. \& Diamond, L.J. (1979). "Effects of investment dependence on economic growth. The role of internal structural characteristics and periods in the world economy", International Studies Quarterly 23: 412-444.

Hansen, T. (1981). "Transforming needs into expenditure decisions", pp. 27-47 in K. Newton (ed.), Urban Political Economy. London: Frances Pinter.

Johnston, J.J. (1972). Econometric Methods. 2nd edn. New York: McGraw-Hill.

Laakso, M. \& Taagepera, R. (1979). " 'Effective' number of parties, a measure with application to West Europe", Comparative Political Studies 12: 3-27.

Lange, P. \& Garrett, G. (1985). "The politics of growth: strategic interaction and economic performance in the advanced industrial democracies, 1974-1980", Journal of Politics 47: $792-827$.

Lazarsfeld, P.F. (1955). "Interpretation of statistical relations as a research operation", pp. 115-125 in P.F. Lazarsfeld \& M. Rosenberg (eds), The Language of Social Research. New York: Free Press of Glenco.

Letterie, J.W. \& Van Puijenbroek, R.A.G. (1985). "Welfare policies: the interaction effects of collective demands and liberal democracy in a cross-sectional analysis of 115 countries", Acta Politica 20: 331-352.

Marsden, P.V. (1981). "Conditional effects in regression models", pp. 97-116 in P.V. Marsden (ed.), Linear Models in Social Research. Beverly Hills: Sage.

Morris, J.H., Sherman, J.D. \& Mansfield, R. E. (1986). "Failures to detect moderating effects with ordinary least squares-moderated multiple regression: some reasons and a remedy", Psychological Bulletin 99: 282-288.

Pedersen, M.N. (1983). "Chancing patterns of electoral volatility in European party systems 1948-1977: explorations in explanation", pp. 29-66 in H. Daalder and P. Mair (eds), Western European Party Systems: Continuity and Change. Beverly Hills: Sage.

Smith, K.W. \& Sasaki, M.S. (1979) "Decreasing multicollinearity, a method for models with multiplicative functions", Sociological Methods \& Research 8: 35-56.

Southwood, K.E. (1978). "Substantive theory and statistical interaction", American Journal of Sociology 83: 1154-1203.

SPSS $^{\times}$(1986). SPSS ${ }^{\times}$User's Guide. New York: McGraw-Hill.

Stolzenberg, R.M. (1979). "The measurement and decomposition of causal effects in nonlinear and non-additive models", pp. 459-488 in K.F. Schuessler (ed.). Sociological Methodology 1980. San Francisco: Jossey-Bass.

Tate, R.L. (1984). "Limitations of centering of interactive models", Sociological Methods \& Research 13: 251-271.

Van Puijenbroek, R.A.G. \& Van Snippenburg, L.B. (1985). "Internationale arbeidsdeling, afhankelijkheid en economische groei: een cross-nationale studie", Acta Politica 20: 385-419.

Weede, E. (1987). "Interaction effects in cross-national studies. Human capital formation, Government revenues and economic growth in less developed countries", Quality \& Quantity 21: 361-375.

Weisberg, S. (1980). Applied Linear Regression. New York: John Wiley \& Sons. 